\title{
Use of oral voriconazole as adjunctive treatment of severe cornea fungal infection: case report
}

\author{
Usodo voriconazol oral como tratamento adjuvante da infecção fúngica gra ve \\ da córnea: relato de caso
}

Roberto Freda*

Trabalho realizado no curso de Especialização em Oftalmologia do Hospital Banco de Olhos de Porto Alegre.

* Mestre em Oftalmologia pela Escola Paulista de Medicina, Universidade Federal de São Paulo - UNIFESP; Preceptor do Setor de Córnea e Doenças Externas do Hospital Banco de Olhos de Porto Alegre - Porto Alegre (RS) - Brasil.

Endereço para correspondência: Rua Araponga, 194 - Porto Alegre (RS) CEP 91330-130

Recebido para publicação em 07.04.2005

Versão revisada recebida em 02.11 .2005

Aprovação em 08.01.2006

Nota Editorial: Depois de concluída a análise do artigo sob sigilo editorial e com a anuência da Dra. Marta Beatriz Filippi Sartori sobre a divulgação de seu nome como revisora, agradecemos sua participação neste processo.

\begin{tabular}{|l|}
\hline \multicolumn{1}{|c|}{ ABSTRACT } \\
\hline A case of Aspergillus flavus keratitis was successfully treated with oral \\
voriconazole and penetrating keratoplasty after conventional antifungal \\
medical therapy failure.
\end{tabular}

Keywords: Fluconazole/therapeutic use; Eye infections, fungal/drug therapy; keratitis; Antifungal agents/therapeutic use; Case reports [publication type]

\section{INTRODUCTION}

We present a case of severe fungal infection of the cornea in which systemic oral voriconazole was used as an adjunct therapy after conventional antifungal medical therapy failure. This case report may warrant additional investigation on the role of this anti-fungal agent to treat severe mycotic corneal infection.

\section{CASE REPORT}

A 40-year-old man presented with history of corneal ulcer treatment in the left eye in the previous week: Tobradex ${ }^{\circledR}(0.3 \%$ tobramycin $-3 \mathrm{mg}, 0.1 \%$ dexamethasone $-1 \mathrm{mg}$, and $0.01 \%$ benzalkonium chloride preservative) and Maxitrol ${ }^{\circledR}$ (polymyxin B sulfate, neomycin sulfate, and $0.1 \%$ dexamethasone - $1 \mathrm{mg}$ ) drops. This regimen was ineffective and the patient was referred to a second opinion.

At presentation, visual acuity was normal (20/20) in the right eye and $20 / 200$ in the left eye. There was slight lid edema and moderate conjunctival and pericorneal injection. A corneal epithelial defect measuring 2 x $2 \mathrm{~mm}$ with an infiltrate (abscess) was observed, surrounded by a small amount of stromal edema, with a small amount of mucopurulent material covering the base of the ulcer and at the inferior fornix. The ulcer had a deep central ulceration and the abscess with indistinct margins involving the paracentral corneal zone. There was anterior chamber reaction $(1+/ 4+)$ and a discrete hypopyon of $0.5 \mathrm{~mm}$ in height. Lens and fundus examinations were normal (Figure 1).

The patient denied any trauma, systemic disease or use of contact lens. Specimens were collected by scraping the margin of the abscess and bed of the corneal ulcer, which were submitted to bacteriological and mycological analysis. Scrapings were inoculated onto blood agar, brain heart infusion (BHI) and Sabouraud agar. Gram stain showed gram-positive cocci. Further results did not identify any culture growth. 


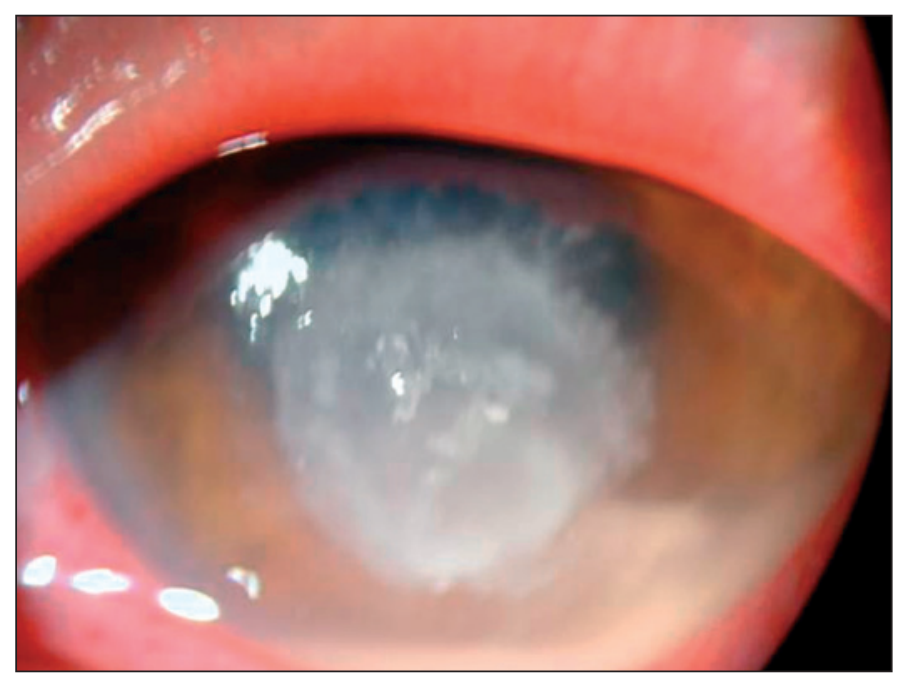

Figure 1 - A $2 \times 2 \mathrm{~mm}$ corneal epithelial defect with abscess and a stromal edema, mucopurulent material covering the base of the ulcer. The ulcer had a deep central ulceration and the abscess showed indistinct margins involving the paracentral corneal zone. There was anterior chamber reaction and a discrete hypopyon of $0.5 \mathrm{~mm}$ in height.

As suggested by the gram stain, the patient was treated initially with fortified antibiotics $(50 \mathrm{mg} / \mathrm{ml}$ cefazolin and $1 \mathrm{mg} / \mathrm{ml}$ amicacin) and fourth generation fluoroquinolone (gatifloxacin) hourly. Dilating drops (1\% ciclopentolate) every eight hours were also instituted. The patient was examined every day. As time went by, the corneal condition seemed to improve slightly and treatment with $1 \%$ dexametasone twice daily to decrease the inflammation of the eye. However, by day 12 of treatment (5 days on corticosteroid), the infiltrate seemed to be growing in extension and some adjacent whitish lesions (satellite lesions) were observed which led to the suspicion of fungal infection (Figure 2).

Corticosteroid treatment was discontinued immediately

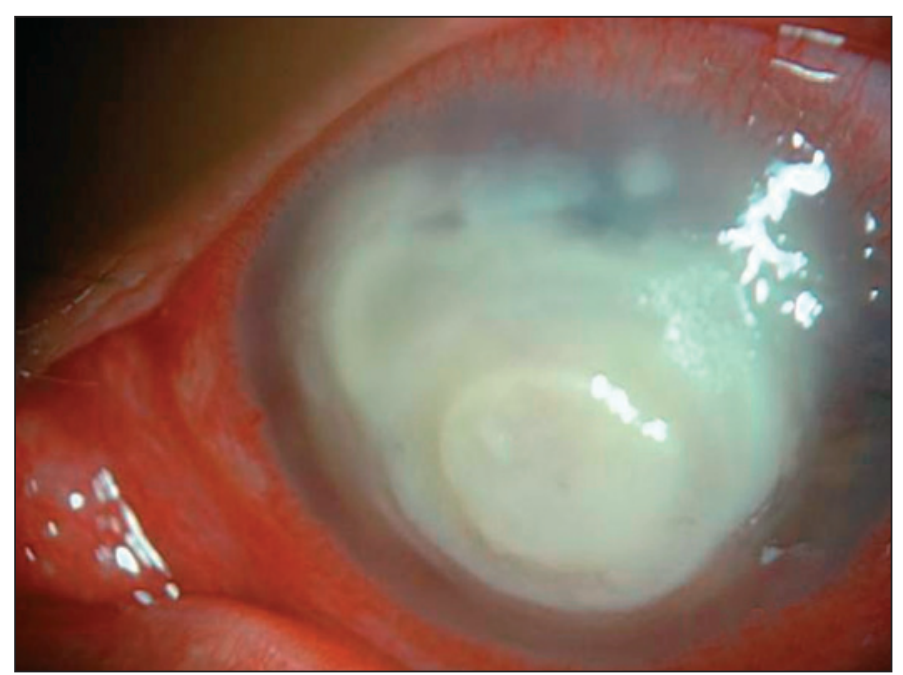

Figure 2 - After five days on corticosteroid, the infiltrate extension increased and some adjacent whitish lesions (satellite lesions) that raised the suspicion of fungal infection were observed and the patient started on $0.15 \%$ amphotericin B and 5\% natamicin drops hourly and oral ketoconazole (200 $\mathrm{mg}$ twice daily). It is worth noting that at that time, laboratory results had not yielded any culture growth and the treatment was based on the history told by the patient (abrupt onset of symptoms), clinical aspects (compatible with bacterial ulcer) and the gram stain (also compatible with bacterial infection). Despite this regimen of treatment, the aspect of the cornea had not improved and it was actually enlarged (Figure 3).

As the cornea worsened, another scraping was performed for further analysis. At the same time, a corneal biopsy was also performed. The laboratory results revealed filamentous fungal infection (Aspergillus flavus). In three days, infiltration of the cornea and the hypopyon had greatly increased. Intracameral amphotericin B (10 micrograms) was employed twice. It has been shown that intracameral amphotericin B does not cause corneal or lenticular toxicity and it has been used with success in anecdotal cases of Aspergillus flavus keratitis ${ }^{(1)}$. Despite this procedure, the infiltrate extended to the limbus and the cornea started to melt (Figure 4).

Oral voriconazole was initiated (200 mg p.o. daily). In face of an impending perforation, cornea transplantation was performed (Figures 5 and 6). Although the cornea the Eye Bank released was meant to be for a tectonic transplantation, the graft remained clear and with no signs of either infection or rejection, more that 2 months after the corneal transplantation. Initially, the patient was kept on topical cyclosporine twice daily $\left(\operatorname{Restasis}^{\circledR}\right)$, due to the fact that corticosteroids were kept until there were no signs of fungal relapse.

As time passed and there was no sign of fungal infection remission, low-dose corticosteroid was initiated to minimize eye inflammation. Alrex ${ }^{\circledR}$ twice daily was started (for 1 week) then switched to Loteprol $^{\circledR}$ twice daily (for 1 week). After there was confidence that there was no infection, Minidex ${ }^{\circledR}$ twice daily was initiated (for 1 week) and then switched to Maxidex ${ }^{\circledR}$

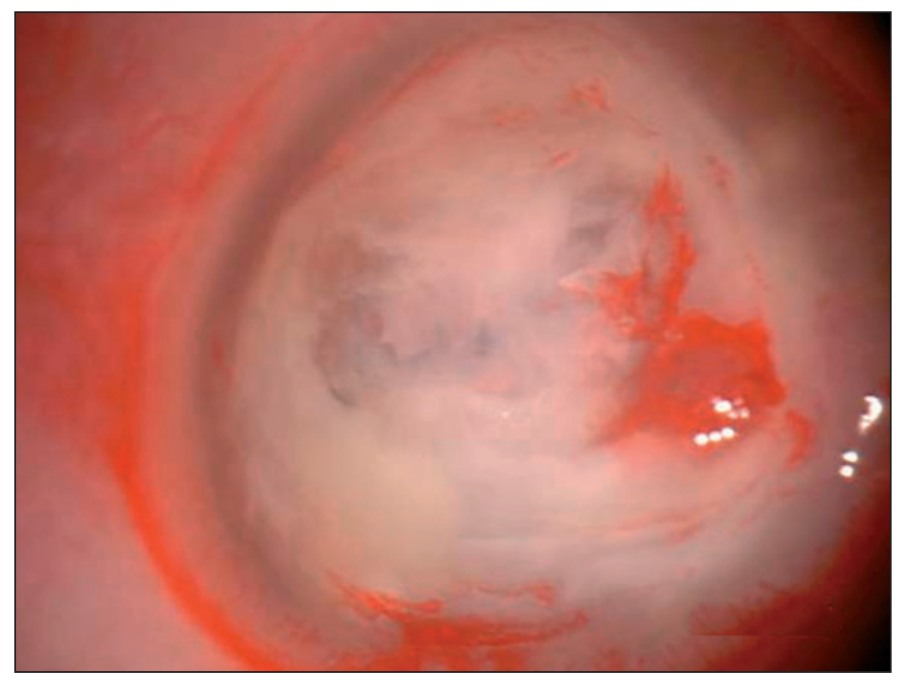

Figure 3 - Despite the treatment, the aspect of the cornea had not improved and the ulcer had enlarged 


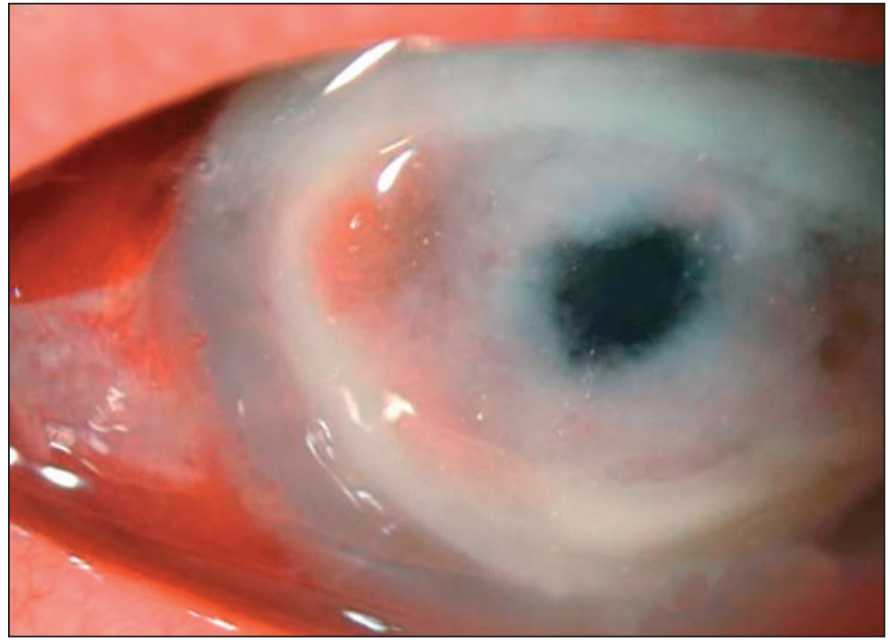

Figure 4 - The infiltrate extended to the limbus and the cornea started to melt

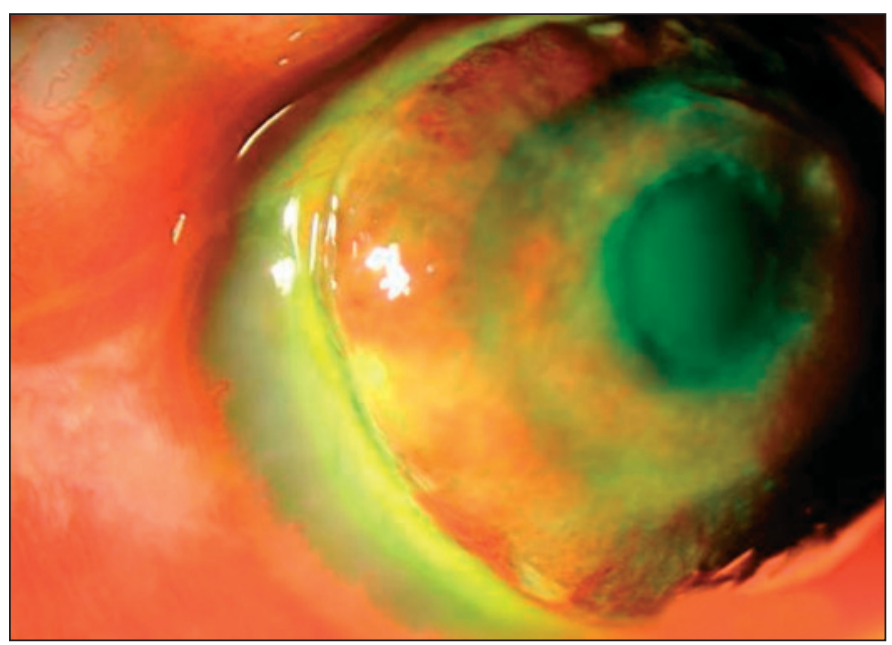

Figure 5 - Cornea with an impending perforation

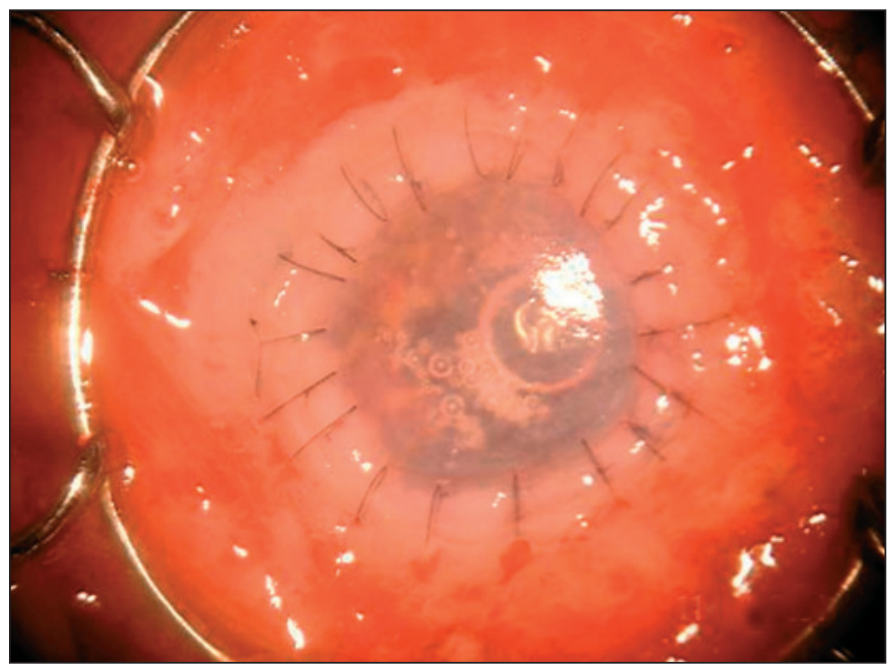

Figure 6 - In face of an impending perforation, a cornea transplantation was performed twice a day. The patient has been kept on this regimen for 2 weeks and cyclosporine has been discontinued.

On the last visit, three months after the corneal transplantation, the graft remained clear and the best corrected visual acuity with contact lenses was 20/30, though we do not yet intend to fit them. We expect to start fitting contact lens after at least 12 months of clear graft.

\section{DISCUSSION}

Fungal corneal infection is a vision-threatening condition that may present in a challenging way. It has been demonstrated that the use of topical corticosteroid may predispose to the onset and the worsening of the fungal infection of the eye. Despite aggressive treatment, the here described patient, was irresponsive to the medical therapy.

Filamentous fungi are more common in patients with a history of trauma of the eye, especially with vegetal material. More rarely, Aspergillus flavus may cause severe infection of the cornea after laser in situ keratomileusis ${ }^{(2)}$. It has been shown that intracameral amphotericin B does not cause corneal or lenticular toxicity and has been used with success in anecdotal cases of Aspergillus flavus keratitis $^{(1)}$. On the other hand, patients with previous use of corticosteroid are more prone to Candida-like infections.

The drugs available to treat infections of the eye with fungi are limited. Moreover, their penetration into the eye is limited. The case of a fungal corneal infection treated with a new antifungal agent (voriconazole) with very good result is reported in this article.

Searching the medical literature, a paper reporting the use of oral voriconazole with great success was found, though in this case it was not a keratomycosis caused by Aspergillus flavus ${ }^{(3)}$.

A study by Hariprasad ${ }^{(4)}$ demonstrated that orally administered voriconazole reaches therapeutic aqueous and vitreous levels in the noninflamed human eye and that the activity spectrum appears appropriately to encompass the most frequent encountered mycotic species involved in the various causes of fungal eye infection.

We considered that oral voriconazole might be important in attempting to prevent further spread of the fungus to the interior of the eye, since the transplantation of the cornea alone would not have been sufficient to keep the fungus in the anterior portion of the eye, because the periphery of the cornea was already compromised and Descemet's membrane had been breached.

Some papers demonstrated in the aqueous a concentration more than $50 \%$ than that in plasma and almost seven times higher than the MIC for Scedosporium apiospermum strain. Hua et at ${ }^{(5)}$ demonstrated that intravitreal voriconazole of up to $25 \mathrm{microgram} / \mathrm{ml}$ causes no ERG change or histologic abnormality in rat retina. This may indicate that voriconazole 
is a safe antifungal agent that may be employed by intravitreal injection in the treatment of fungal infections of the eye.

We could not find any study on the topical concentration of cyclosporine used in this case $(0.05 \%)$, although higher doses have shown to be of some clinical effectiveness ${ }^{(6)}$.

\section{CONCLUSIONS}

This case report shows that severe fungal eye infections may benefit from the use of adjunct systemic voriconazole. Further studies on animal models may determine the appropriate timing and dose of this promising drug.

\section{RESUMO}

O presente trabalho descreve o emprego do voriconazol sistêmico como adjuvante no tratamento de ceratite micótica grave por Aspergillus flavus.
Descritores: Fluconazol/uso terapêutico; Infecções oculares fúngicas/quimioterapia; Ceratite; Antimicóticos/uso terapêutico; Relatos de casos [tipo de publicação]

\section{REFERENCES}

1. Kaushik S, Ram J, Brar GS, Jain AK, Chakraborti A, Gupta A. Intracameral amphotericin B: initial experience in severe keratomycosis. Cornea. 2001;20(7): 715-9.

2. Sridhar MS, Garg P, Bansal AK, Gopinathan U. Aspergillus flavus keratitis after laser in situ keratomileusis. Am J Ophthalmol. 2000;129(6):802-4.

3. Nulens E, Eggink C, Rijs AJ, Wesseling P, Verweij PE. Keratitis caused by Scedosporium apiospermum successfully treated with a cornea transplant and voriconazole. J Clin Microbiol. 2003;41(5):2261-4.

4. Hariprasad SM, Mieler WF, Holz ER, Gao H, Kim JE, Chi J, Prince RA. Determination of vitreous, aqueous, and plasma concentration of orally administered voriconazole in humans. Arch Ophthalmol. 2004;122(1):42-7.

5. Hua G, Pennesi M, Shah K, Qiao X, Hariprasad SM, Mieler WF, et al Safety of intravitreal voriconazole: electroretinographic and histopathologic studies. Trans Am Ophthalmol Soc. 2003;101:183-9; discussion 189.

6. Bell NP, Karp CL, Alfonso EC, Schiffman J, Miller D. Effects of methylprednisolone and cyclosporine A on fungal growth in vitro. Cornea. 1999;18(3): 306-13.

\section{9* Congresso de Oftalmologia e 8 - Congresso de Auxiliar da USP}

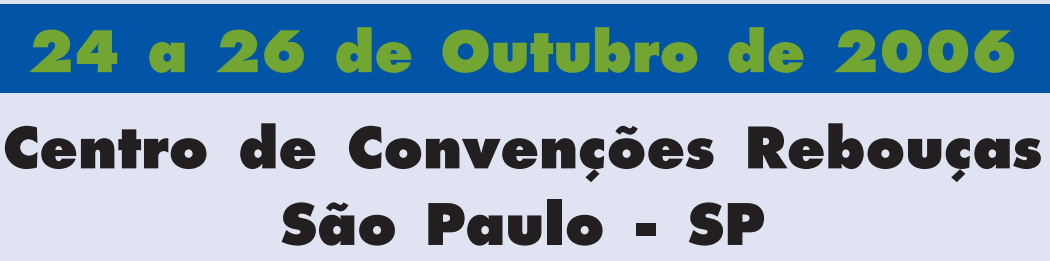

INFORMAÇÕES: Tel.: (1 1 ) 5575-0254 - Fax: (11) 5539-2186

E-mail: info@congressousp.com.br

Home page: www.congressousp.com.br 